\title{
Agri Image Processing using Uml Model
}

\author{
Suguna $\mathrm{M}^{1}$, S. Nithya Priya ${ }^{2}$ and G. Thenmozhi ${ }^{3}$ \\ ${ }^{1}$ Associate Professor, Information Science and Engineering \\ Department, Kumaraguru College of Technology, Coimbatore, India \\ ${ }^{2}$ Assistant Professor (SrG), Biotechnology Department, Kumaraguru \\ College of Technology, Coimbatore, India \\ ${ }^{3}$ Associate Professor, Automobile Engineering Department, Kumaraguru \\ College of Technology, Coimbatore, India
}

\section{ABSTRACT}

Agri image processing is an undertaking which points in building up a mechanized framework to separate and investigate leafy foods as great and terrible through an image handling framework. To check the nature of Agri-products through image processing handling utilizing MATLAB ide. It points in lessening human endeavors in the field of farming where there is an enormous region of land and it cannot check every yield physically, in this way fruits quality to check the nature of the product. Generally, this task of own is being created to support the customers, Businesspeople and Industrialists spare their time. It additionally helps in conveying great quality items to the Clients. This venture is helpful for both the merchants and purchasers of Agri-items.

KEY WORDS: AGRI PRODUCT, FRUIT ANALYSIS, FRUIT, SORTING, GRADING, PSNR.

\section{INTRODUCTION}

Agri image handling is a venture which points in building up a mechanized framework to separate and examine leafy foods as great and find the quality of the product through an image processing Preparing Framework. In this cycle to recognize the Nature of Horticulture items whether they are Positive or negative by utilizing the IAQ (image quality evaluation) using various parameters of pixel composition ratio Filter and measure MSE, PSNR, SNR of single image. In image methoding, helpless picture quality is pitiful for viable component extraction, include examination, design acknowledgment and quantitative

\section{ARTICLE INFORMATION}

*Corresponding Author: suguna.m.cse@kct.ac.in

Received 12th Oct 2020 Accepted after revision 24th Nov 2020

Print ISSN: 0974-6455 Online ISSN: 2321-4007 CODEN: BBRCBA

Thomson Reuters ISI Web of Science Clarivate Analytics USA and Crossref Indexed Journal

\section{Clarivate
Analytics}

NAAS Journal Score 2020 (4.31) SJIF: 2020 (7.728)

A Society of Science and Nature Publication,

Bhopal India 2020. All rights reserved.

Online Contents Available at: http//www.bbrc.in/

Doi: http://dx.doi.org/10.21786/bbrc/13.11/2 mensuration. the photos are unexceptionally defiled by irregular commotion that occurs all through the estimation cycle in this manner confusing the robotized highlight extraction and examination of clinical Therefore, noisy images disposal might be an ought to for clinical pictures cycle to dispose of such demands while retentive the greatest sum as likely the vital picture[10]. Test cases are used to find the product good quality or bad quality.

\section{MATERIAL AND METHODS}

Literature Survey: The investigation done by a few scientists in the zone of picture order, foods grown from the ground characterization, natural products acknowledgment, natural product sickness [2] have proposed framework which discovers size of various products of the soil various natural products can be arranged utilizing fluffy rationale, here creator proposed MATLAB for the highlights extraction and for creating product of the soil order and natural product upset ID is viewed as a happening of image arrangement. The overwhelming majority of the explorers within the field of natural product acknowledgment or natural product

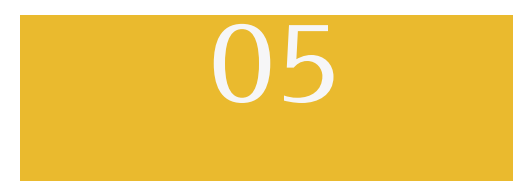


illness location have thought-about tone and surface properties for the order [5]. Review and management quality, one should have the option to quantify qualityrelated credits. During this paper $[7,8]$ because of the high damp content in the product of the soil, water rules $\mathrm{X}$-beam ingestion. A person's critical examination and reviewing of manufacture is usually a piece escalated, dreary, tedious, and emotional enterprise [6]. nevertheless, its costs, this system is variable, and decisions are not typically inevitable between assessors or from everyday [4]. The laptop vision examination of food things to be sensible, skilled, and reliable.

Proposed System: Projected framework explanation for this report is to assemble an application to visualize nature of Agri-items through image handling utilizing
MATLAB ide. As huge sections of land cannot be checked physically, subsequently picture handling is utilized to check the nature of the yield. The accompanying strides to construct the following three steps. Step-1: A landing page which shows different alternatives (about, help, cycle, exit.) and screen where you can transfer a picture of the yield.

Step-2: Then convert the offered picture to highly contrasting for preparing and office to change over a given picture into good size and goal at that point apply a channel for extra handling of data. Step-3: Analysis of the picture depends on a couple of highlights like MSE, PSNR, SNR, SC... and so on and screen which shows the eventual outcome of the picture as fortunate or unfortunate.

\begin{tabular}{|c|c|}
\hline Functional requirements & Non-functional requirements \\
\hline $\begin{array}{l}\text { Product Perspective } \\
\text { A distributed image processing } \\
\text { database system includes description } \\
\text { of the product and stores the following information. }\end{array}$ & $\begin{array}{c}\text { Performance Perspective } \\
\text { To store all the farming information } \\
\text { base are as recorded } \\
\text { underneath UML diagram }\end{array}$ \\
\hline $\begin{array}{l}\text { Product Features } \\
\text { Agricultural yields are tested by } \\
\text { traditional methods which consume labour. } \\
\text { On the other hand, image processing } \\
\text { techniques help to check quality of } \\
\text { yields thus reducing manual labour. }\end{array}$ & $\begin{array}{l}\text { Safety Requirements } \\
\text { If there is broad harm to a wide segment } \\
\text { of the information base because } \\
\text { of disastrous disappointment. }\end{array}$ \\
\hline $\begin{array}{l}\text { User Class: Clients of the framework ought } \\
\text { to have the option to recover yield data } \\
\text { between given agricultural- products with the } \\
\text { given image related data from the } \\
\text { database. The software can be } \\
\text { used by both sellers } \\
\text { and buyers. }\end{array}$ & $\begin{array}{c}\text { Security Requirements } \\
\text { Security frameworks need information } \\
\text { base stockpiling simply like numerous } \\
\text { different applications. In any case, the } \\
\text { exceptional prerequisites of the security market } \\
\text { imply that merchants must pick } \\
\text { their information base accomplice cautiously. }\end{array}$ \\
\hline $\begin{array}{l}\text { Working Environment } \\
\text { Working climate for the quality } \\
\text { testing framework is as recorded } \\
\text { using the MATLAB platform. } \\
\text { Design and Implementation Constraints }\end{array}$ & $\begin{array}{l}\text { Software Quality Attributes } \\
\text { Correctness: The quality of the processed } \\
\text { image must be accurate. } \\
\text { Maintainability and Usability: All the data must } \\
\text { be stored safely, and the product ought to } \\
\text { fulfil the greatest number of client's needs. } \\
\text { It ought to be helpful to utilize. }\end{array}$ \\
\hline
\end{tabular}

Preprocessing: Pictures gained by different kinds of methods comprise of numerous commotions which disintegrate the part of a picture. In this manner, it cannot contribute fitting information for picture preparing. The Preprocessing upgrades the picture information, which beat hesitant twists and grow the highlights of the picture that are fundamental for handling and manufacturing an important picture than the first for a clear application. Component pre-processing modifications over associate degree information picture into a yield picture with the top goal that every yield pixel is said to the data pixel having the examination The farthest regular technique for pixel pre-preparing is shading for appraisal of food quality.

Uml Diagram: The organic products submit the request, which is put away into an information base. The request is prepared and after completed it is refreshed into the information base. A testing is produced, and the client is sent a notice to get the request. To check for quality and status. This segment will straightforwardly utilize the product to do these capacities. The segment will be relegated to an interesting id for each product of the soil request they place, for recognizable proof. The request 
segment will hold all the information given by the client The information base part assumes a significant function in putting away, getting to, sorting out the information given by the client. This part utilizes a table with a few fields to store the information as needs be. This must be gotten to by the Admin of the shop, client segment has no admittance to it. Mistakes in this part can mess major up like losing all information, so it should consistently be kept up and upheld. Figure 1,2,3,4 and 5 represents UML diagram of various flow of activity class, sequential, flow diagram and component diagram.

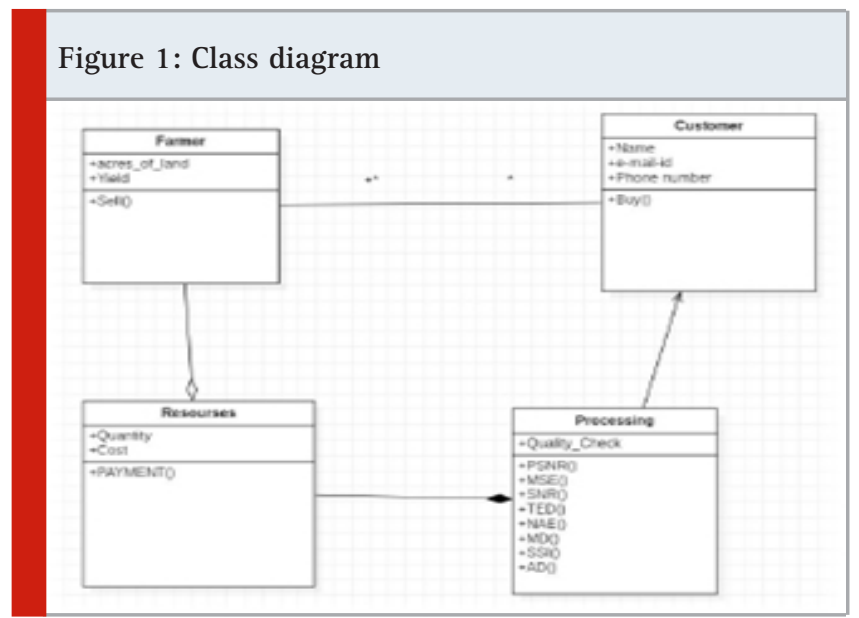

Figure 2: Sequence diagram

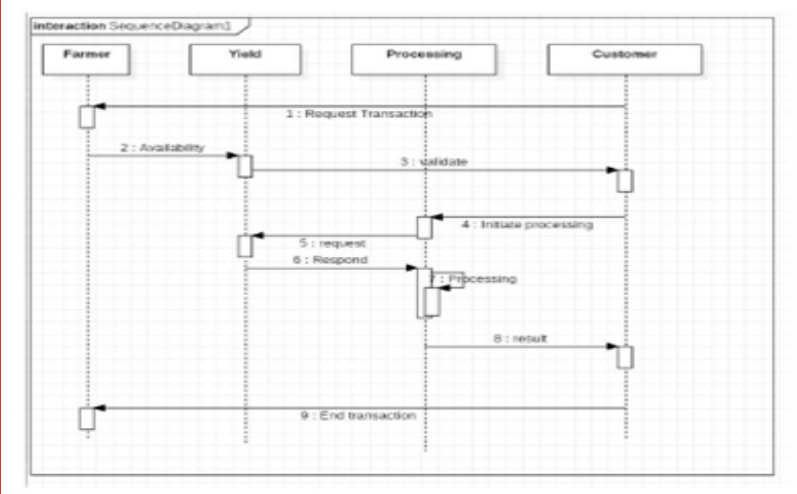

Figure 5: Component diagram

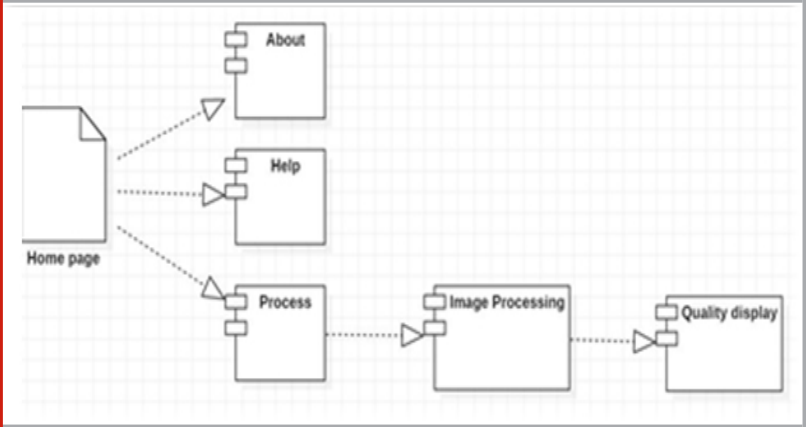

Testing Phase: Quality checking of rural items is created easy through image preparing. are often a tool that has unimaginable breadth in future. As innovation improves
Figure 3: Activity diagram

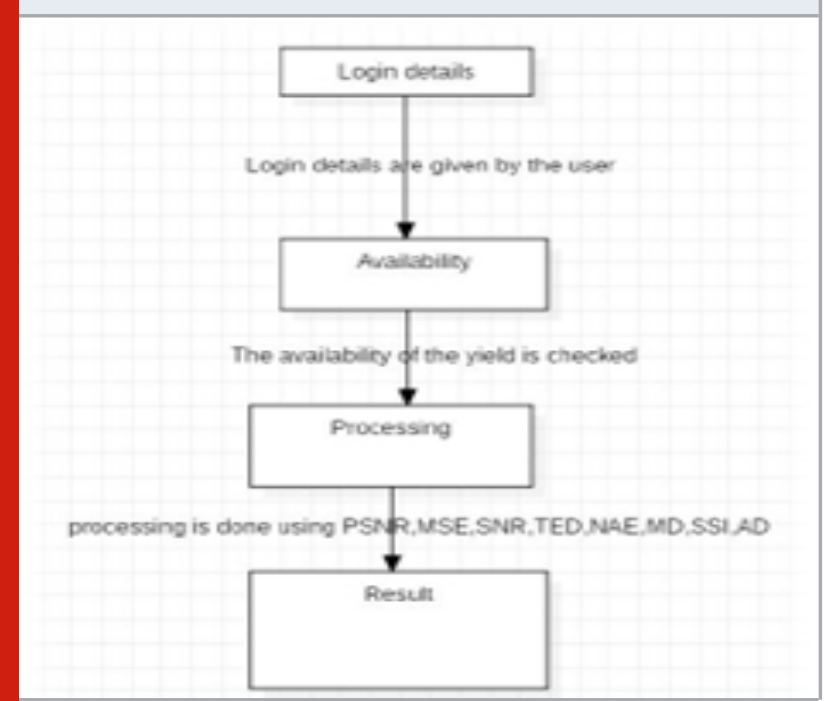

Figure 4: Data Flow diagram

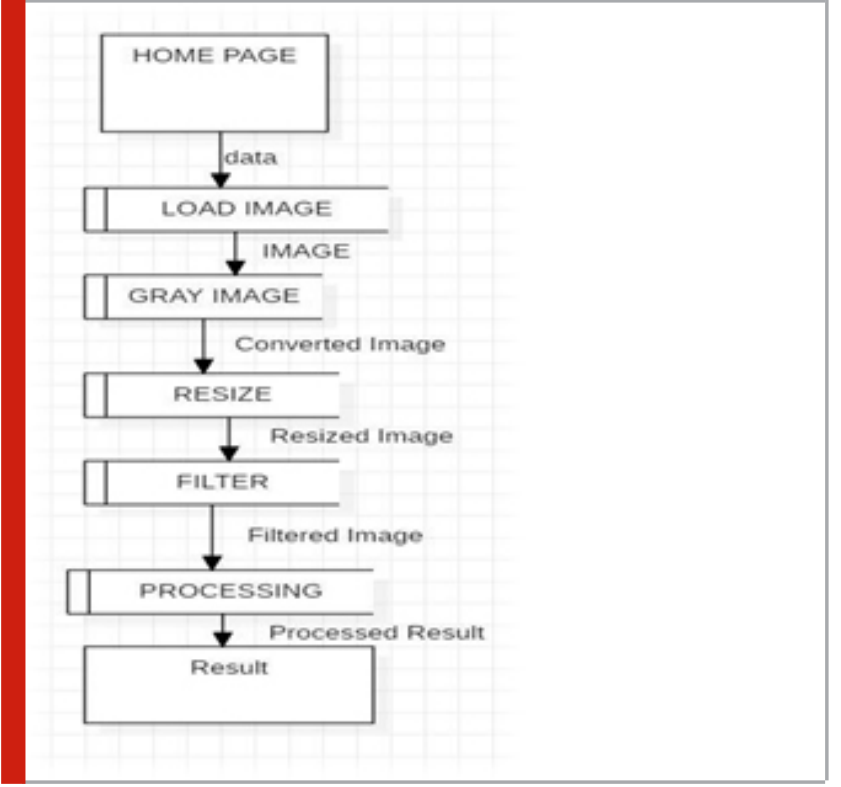

work has been diminishing. Photos of the things can be tried by a progression of steps and therefore the outcomes are obtained in

Associate in Nursing exceptionally temporary timeframe. This prices less work because it decreases the work to travel to the fields to ascertain every item. This may likewise facilitate robots in future to effectively decide and get items in ranches. Imaging can be characterized because of the portrayal of an item's outer structure. That definition does not remain constant. a lot of information within an image may be thought of Future imaging frameworks are needed to be more affordable. they ought to be less complicated to utilize. the use of examining strategies and measurable investigations for picture examination are expected to separate substantial picture esteems. 
Figure 6a: Test case1

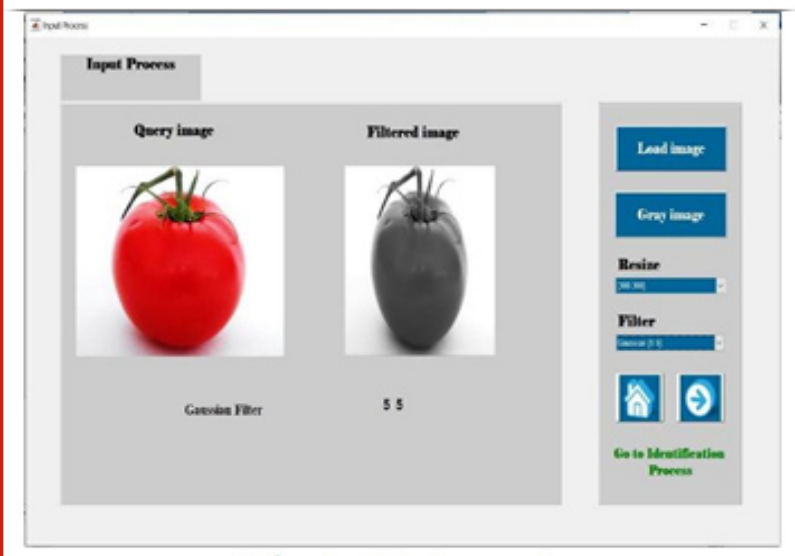

Figure 6b: Result of Test case-1 using IQA parameter

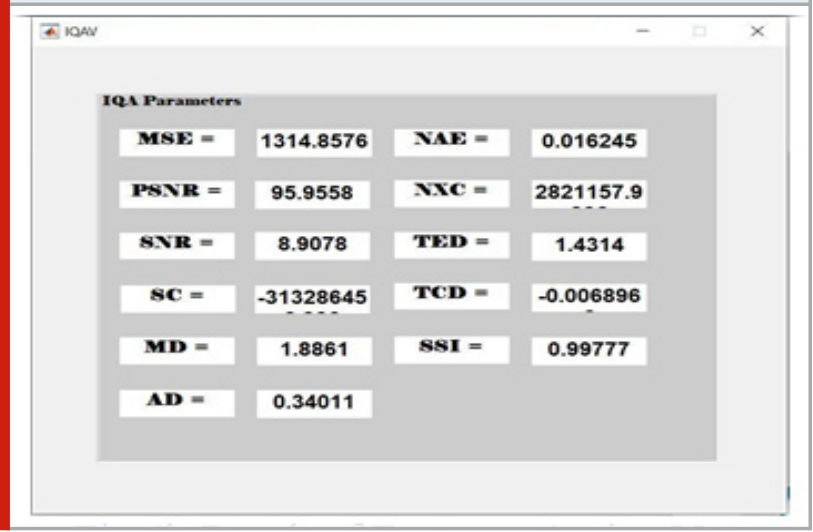

Test case 2

Figure 7a: Test case2

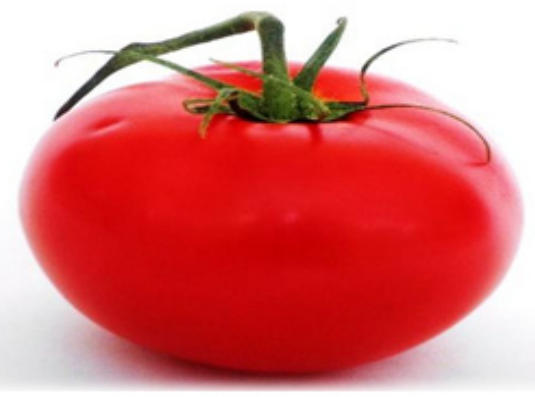

The yield of a product getting ready can be either a product or heaps of attributes or boundaries known with the image. Most product preparing methods embody concerning the product as a two-dimensional sign and applying commonplace sign handling procedures to it. Figure 6,7 and 8 represents the three test cases are identify the Quality Assessment of Agricultural things The optimization tools was used for estimating the assimilation and diminished dissipating coefficients for an assortment of plant items and for Be that
Figure 6c: Result of Test case 1

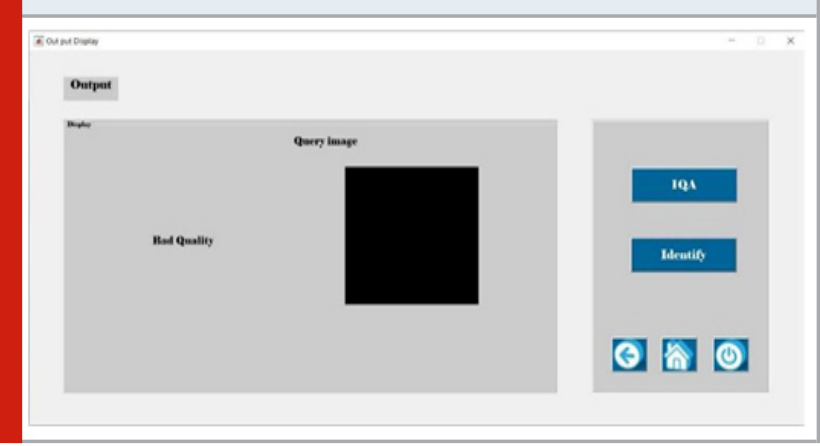

Figure 7b: Result of Test case-2using IQA parameter

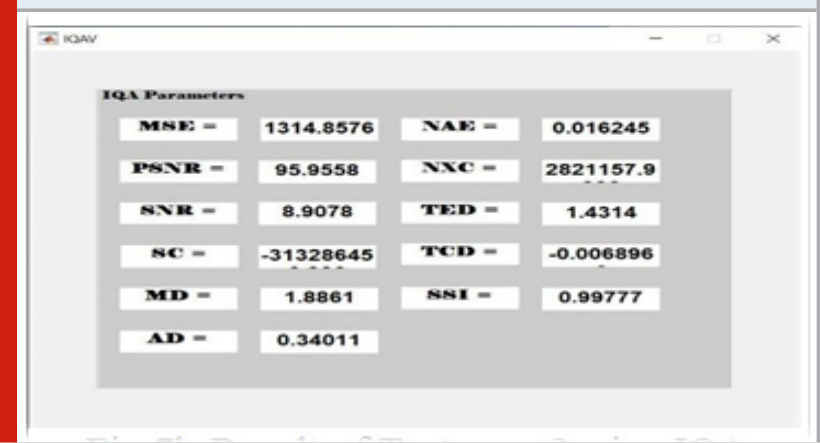

Figure 7c: Result of Test case 2

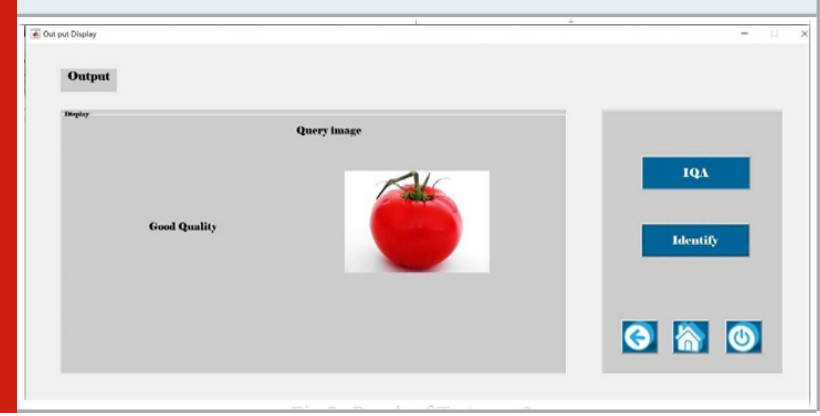

Test case 3

Figure 8a: Test case 3

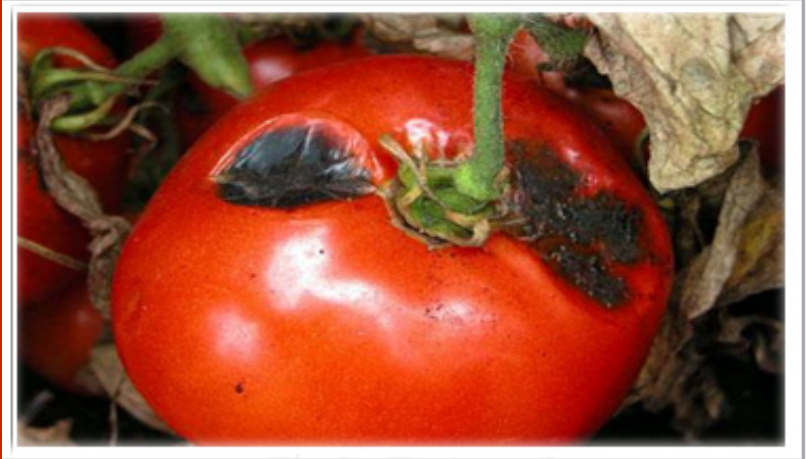

because it may, the strategy needs perplexed numerical demonstrating and is inclined to mistake throughout the image getting and bend fitting. 
Figure 8b: Result of Test case-3using IQA parameter

Then

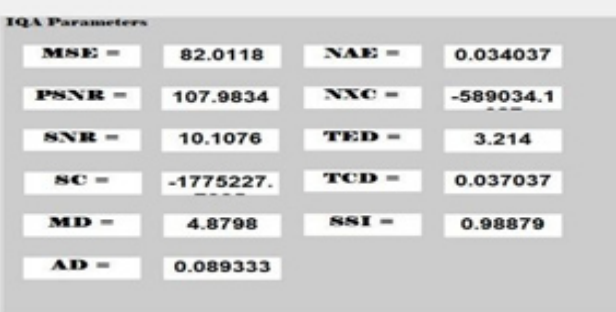

Figure 8c: Result of Test case3

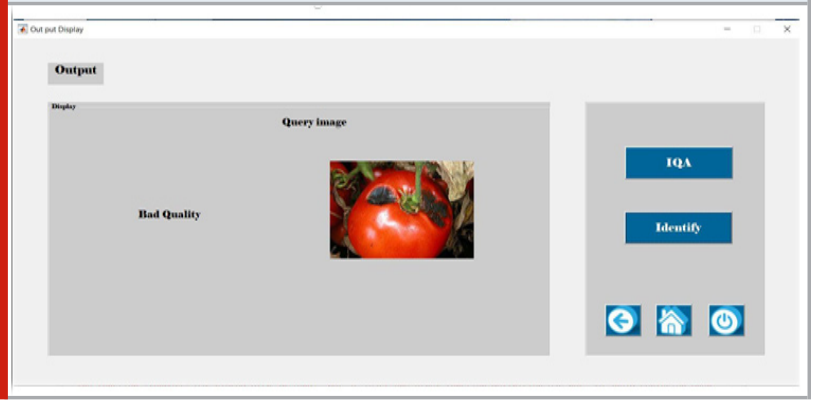

Also, the strategy presently is simply affordable for center use as a result of moderate imaging and knowledge getting ready speed. additional work to boost the accuracy and speed for optical property estimation.

\section{CONLUSION}

A big take a look at for programmed image examination is that the sheer varied nature of the visual assignment that has been New innovative advancement within the territories of computerized calculation Associate in Nursing and media transmission has significance for future utilizations of picture. This innovation is required for different types of observation, measurable data assortment in the fields of customer service to identify the quality of the product therefore as to remove bad quality product to sale in market.

\section{REFERENCES}

A Fruit Quality Management System Based on Image Processing, Volume 8, Issue 6 (Nov. - Dec.2013)

Fruit Quality Management using Image Processing Mr. Sumit S. Telang, Prof. S.M.Shirsath in International Conference on Ideas, Impact, and Innovation in Mechanical Engineering, volume: 5, issue: 6727 $-733(2017)$

https://in.mathworks.com/videos/introduction-tomatlab-with-image-processing-toolbox-90409.html https://staruml

Iza Sazanita Isa, Siti Noraini Sulaiman, Muzaimi Mustapha, Sailudin Darus.Evaluating Denoising Performances of Fundamental Filters for T2-Weighted MRI Images”, Procedia Computer Science, 2015.

Plant Disease Classification Using Image Segmentation and SVM Techniques K. Elangovan, S. Nalini International Journal of Computational Intelligence Research ISSN 0973-1873 Volume 13, Number 7 (2017), pp. 18211828

Quality measurement of fruits and vegetables, Judith A. Abbott Received 30 June 1998; accepted 11 Nov.1998 Rapid Color Grading for Fruit Quality Evaluation Using Direct Color Mapping, Published in Automation Science and Engineering, IEEE Transactions on, Volume:8, Issue: 2, 2010

Tao, Y., Heinemann, P.H., Varghese, Z., Morrow, C.T., Sommer, H.J., "III, Machine vision for colour inspection of potatoes and apples", Transactions of the ASAE, 38(5), pp.1555-1561,1995a.

XuQiabao, Zhou Xiaobo, and Zhao Jiewen, "On-Line Detection of Defects on Fruit by Machine vision Systems Based on Three Color-Cameras Systems," Computer and Computing Technologies in Agriculture II, vol. 3, pp. 2231-2238, 2009. 